\title{
Çocukları Böbrek Transplantasyonu Olan Ailelerin Psikolojik Dayanıklılığı
}

\author{
Psychological Resilience of Families with Children \\ with Kidney Transplantation
}

\author{
Satı DOĞAN ${ }^{1}$, Eda ÇELİ ${ }^{2}$, Kezban ÖZTÜRK $^{3}$, Sabri AYDEMIR ${ }^{4}$
}

${ }^{I}$ Dr. Öğr. Üyesi- Ege Üniversitesi Hemşirelik Fakültesi, Ruh Sağllğı ve Hastalkkları Hemşireliği AD, İzmir, Türkiye

${ }^{2}$ Hemşire- İstanbul Amerikan Hastanesi, İstanbul, Türkiye

${ }^{3}$ Hemşire- Özel Sada Hastanesi, İzmir, Türkiye

${ }^{4}$ Hemşsire-Sağllk Bilimleri Üniversitesi, Tepecik Eğitim ve Araştırma Hastanesi, İzmir, Türkiye

Geliş Tarihi / Received:

14 Eylül 2020

Kabul Tarihi / Accepted:

27 Eylül 2020

\section{İletişim yazarı \\ Correspondence author}

Satı DOĞAN

E-posta: sdbozkurt@hotmail.com

\section{ORCID:}

Satı DOĞAN

https://orcid.org/0000-0002-9935-3265

Eda ÇELIK

https://orcid.org/0000-0003-0914-5436

Kezban ÖZTÜRK

https://orcid.org/0000-0002-4052-4322

Sabri AYDEMIR

https://orcid.org/0000-0002-2766-4822

\section{Özet}

Amaç: Çocukları böbrek transplantasyonu olan ailelerde temel bakım veren aile bireyinin psikolojik dayanıklılıklarını değerlendirmek amacıyla yapılmıştır.

Gereç ve Yöntem: Tanımlayıcı tipte ve kesitsel bir araştırmadır. Araştırmanın evrenini, İzmir'de üçüncü basamak bir eğitim ve araştırma hastanesinin nefrolojidiyaliz ünitesinde çocukları böbrek nakli geçirmiş olan aileler $(\mathrm{N}=55)$ oluşturmuştur. Araştırmanın yapıldığı Mayıs-Haziran 2019 tarihleri arasında tedavi gören çocukların aile üyelerinden temel bakım veren kişilerden araştırma kriterlerini karşılayan ve gönüllü olanlar örnekleme dahil edilmiş̧ir. Araştırmanın verileri kişisel bilgi formu ve Yetişkinler İçin Psikolojik Dayanaklılık Ölçeği ile toplanmıştır. Araştırma sonucunda elde edilen verilerin analizinin bilgisayar ortamında SPSS 20 paket programı ile yapılmıştır. Verilerin değerlendirilmesinde tanımlayıc1 istatistikler, Kolmogorov-Smirnov ve Mann Whitney-U analizleri kullanılmıştır. Sonuçlar \%95 güven aralığında ve $\mathrm{p}<0.05$ anlamlılık düzeyinde değerlendirilmiştir.

Bulgular: Katılımcıların \%9.4'ünün çocuğu 3-12 yaş, \%28.3'ünün 13-17 yaş ve \%62.3'ünün ise 18 yaşını geçmiş olduğu görülmektedir. Çocukların \%60.4'ünün cinsiyeti erkektir. Bakım verenlerin \%79.2'si kadındır. Bakım verenlerin, Psikolojik Dayanıklılık Ölçeği puanları bağımsız değişkenler ile karşılaştırıldığında; ailede başka kronik hastalığı olan bir birey olması, günlük beslenme alışkanlıkları ve özbakım becerileri iyi olan bakım verenlerin psikolojik dayanıklılık puanları istatistiksel olarak anlamlı düzeyde yüksek bulunmuştur $(p<0.05)$. Günlük uyku düzeni, eğitim ve çalışma faaliyetleri, dinlenme ve eğlenme aktiviteleri, spor alışkanlıkları ve sosyal ilişkileri bakım verenlerin psikolojik dayanıklılık puanları açısından istatistiksel olarak anlamlı bir fark yaratmamıştır ( $p>0.05)$.

Sonuç: Ailede başka kronik hastalık olan, günlük beslenme alışkanlığı ve özbakım becerileri iyi olan bakım verenlerin psikolojik dayanıklılığı yüksek bulunmuştur. $\mathrm{Bu}$ da, bakım verenlerin kendileriyle ilgili minimum düzeyde gereksinimleriyle meşgul olduğunu göstermiştir. Günlük uyku düzeni, eğitim ve çalışma faaliyetleri, dinlenme ve eğlenme aktiviteleri, spor alışkanlıkları ve sosyal ilişkiler alanında bakım verenlerin çoğunluğu iyi olmadığını bildirmiştir. Psikolojik dayanıklılıkta önemli etkisi olan bu faktörlerin bakım verenlerin psikolojik dayanıklılıklarına bir etkisi olmaması ilgi çekicidir. Bakım verenlerin; günlük yaşam aktiviteleri, sosyal, entelektüel gereksinimleri ve kendini gerçekleştirme boyutuna ilgi gösteremediği ve bunun özgeci bir davranış olarak kabul görüyor olabileceğini düşündürmüştür.

Anahtar kelimeler: Psikolojik dayanıklılık; Bakım verenler; Böbrek transplantasyonu. 


\begin{abstract}
Objective: This study was carried out to evaluate the psychological resilience of family members whose children had kidney transplantation.

Method: This is a descriptive and cross-sectional study. The universe of the study consisted of families $(\mathrm{N}=55)$ whose children had kidney transplantation in Tepecik Training and Research Hospital Nephrology-Dialysis Unit. Among the family members of children who received treatment between May and June (2019), when the research was conducted, those who met the research criteria and who volunteered were included in the sample. The data of the study were collected using a personal information form and the Adult Psychological Resilience Scale. The analysis of the data obtained as a result of the research was made in a computer environment with SPSS 20 package program. Descriptive statistics, Kolmogorov-Smirnov, Mann Whitney-U analyzes, were used to evaluate the data. Results were evaluated at $95 \%$ confidence interval and $\mathrm{p}<0.05$ significance level.
\end{abstract}

Results: It is observed that $9.4 \%$ of the children of the participants are $3-12$ years old, $28.3 \%$ are $13-17$ years old and $62.3 \%$ are over 18 years old. $39.6 \%$ of the children are girls and $60.4 \%$ are boys. $79.2 \%$ of the caregivers are women and $20.8 \%$ are men. When the Psychological Resilience Scale scores of the caregivers were compared with the independent variables; The psychological endurance scores of caregivers with good daily eating habits and self-care skills were found to be statistically significantly higher $(p<0.05)$. Daily sleep patterns, training, and working activities, resting and recreation activities, sports habits, and social relations did not make a statistically significant difference in terms of psychological endurance scores of caregivers ( $p>0.05)$.

Conclusion: The psychological resilience of caregivers with other chronic diseases in the family and good daily eating habits and self-care skills were found to be high. This showed that the caregivers were preoccupied with the minimal needs of themselves. The majority of caregivers in the areas of daily sleep patterns, training and working activities, recreation and entertainment activities, sports habits, and social relations reported that they were not good. It is interesting that these factors, which have an important effect on psychological resilience, do not affect the psychological resilience of caregivers. It made us think that caregivers may not be interested in their daily life activities, social and intellectual needs, and the dimension of self-actualization, and that might be accepted as altruistic behavior.

Keywords: Psychological resilience; Caregivers; Kidney transplantation.

\section{GİRIŞ}

Organ yetmezliği hayatı tehdit eden sağlık sorunlarındandır ve organ nakli önemli bir çözümdür (1). Kronik böbrek yetmezliği nedeniyle diyalize bağlı yaşam, çocuklarda büyüme ve gelişmeyi ciddi şekilde aksattığı için organ nakli daha da önemlidir (2). Organ naklinin cerrahi ve immünolojik yönlerindeki ilerlemeler, uzun vadeli sonuçlarda ve hayatta kalma oranlarında önemli iyileşmelere neden oldu ve böbrek naklini kronik böbrek hastalığı olan çocuklar için en uygun tedavi haline getirdi $(3,4)$. Ancak, transplantasyon hem çocuğu hem de birinci derece bakım vereni derinden etkiler. Birinci derecede bakım verenler, ilaçların olası yan etkileri, reddedilmeleri değerlendirmek ve tedavi için gerekli ağrılı biyopsiler, hastaneye yatışlar ve okula yeniden uyum konularında çocuğu destekler. Bunlar, bakım sorumluluklarından farklı bir yüktür ve bakım verenin çocuğu günlük yaşantısının merkezine almasını gerektirir. Bakım veren hastalık sürecini etkilediği gibi, süreçten kendisi de etkilenir (5). Mevcut literatür, transplantasyon sürecinin stres verici çeşitli belirsizlik biçimleriyle dolu olduğunu vurgulamaktadır (6). Bunun yanında, Sundaram ve ark. (2007), 26 adölesan böbrek nakli alıcısı üzerinde çalışmışlar ve bakım verenlerin "çocuklarının sağlık durumundan ve 
aile durumlarından" bağımsız olarak önemli düzeyde olumsuz duygusal etkiler ifade ettiklerini bildirmişlerdir (7). Bakım veren kişiler bakımın kendilerine olan etkileri ile baş edememekte ve çaresizlik, suçluluk, öfke, korku ve sosyal izolasyon gibi duygular yaşayabilmektedirler (5). Bu duyguları yaşama ve başetme düzeyleri kişiden kişiye değişmektedir. $\mathrm{Bu}$ değişimi bireylerin psikolojik dayanıklılığı ile açıklayabiliriz. Psikolojik dayanıklılık genel olarak bir başarı veya uyum sağlama sürecini ifade eder (8). Bu çerçevede sağlık sorunları ve diğer önemli zor yaşamsal tecrübeler karşısında kişinin kendisini toparlama gücü veya sorunların başarılı biçimde üstesinden gelme yeteneği olarak da tanımlanmaktadır $(9,10)$. Psikolojik dayanıklılık bireylere zorluklar karşısında dayanma ve mücadele etme gücü vermektedir. Bu gücü taşıyanlar, yaşadıkları olumsuz olaylarda daha çabuk toparlanabilmekte ve eski hayatlarına geri dönebilmektedir. Psikolojik dayanıklılık bazı bireylerde doğuştan bazı bireylerde sonradan edinilen bir özellik olarak görülmüştür. Bireylerin yaşadıkları olaylar sonucunda psikolojik olarak güçlenebildiği ya da bu özelliklerini kaybettikleri fark edilmiştir (11). Psikolojik dayanıklılığın açıklanmasında rol oynayan birçok faktörden söz edilebilmesine karşın; yapılan çalışmalarda bu faktörlerin üç genel kategori altında toplanabileceği öne sürülmektedir (12). Bu kategoriler; aile uyumu ve desteği, kişisel yapısal özellikler ve dışsal destek sistemleri (sosyal çevre, iş arkadaşları vb.) olarak sıralanabilir. Aileler için çocuğun böbrek transplantasyonu stresli bir süreçtir. $\mathrm{Bu}$ süreçte ailelerin psikolojik dayanıklılıklarını etkileyen faktörlerin neler olduğunu tanımlamak amacıyla bu araştırma yapılmıştır. Araştırmadan elde edilen veriler ailelerin psikolojik dayanıklılıklarını etkileyen faktörleri ortaya koyarak, bu alanda uygulama ve araştırmaları yürütecek sağlı profesyonellerine veri oluşturacaktır.

\section{GEREÇ VE YÖNTEM}

\subsection{Araştırmanın tipi ve yeri}

Araştırma, İzmir'de üçüncü basamak bir eğitim ve araştırma hastanesinin nefroloji-diyaliz ünitesinde Mayıs-Haziran 2019 tarihleri arasinda gerçekleştirilmiş, tanımlayıcı ve kesitsel tipte bir çalışmadır.

\subsection{Araștırmanın evreni ve örneklemi}

Araştırmanın evreni, bu hastanenin nefrolojidiyaliz ünitesinde çocukları böbrek nakli geçirmiş olan aileler $(\mathrm{N}=55)$ oluşturmuştur. Araştırmanın yürütüldüğü dönemde kliniğe tedavi için gelen, araştırma kriterlerini karşılayan, gönüllü olan ve çocuğun bakımından sorumlu olan ebeveyn $(\mathrm{n}=53)$ örnekleme dahil edilmiştir.

\subsection{Veri toplama araçları}

Araştırmanın verileri kişisel bilgi formu ve Yetişkinler İçin Psikolojik Dayanaklılık Ölçeği ile toplanmıştır.

Kişisel bilgi formu: Ailelerin, çocuklarının hastalığına karşı psikososyal uyumlarını etkileyebilecek faktörleri ve çocuğun hastalık bilgisini içeren 20 sorudan oluşan bir formdur.

Yetişkinler İçin Psikolojik Dayanaklılık Ölçeği: Yetişkin bireylerin psikolojik dayanıklılık düzeylerini belirlemek amaciyla Friborg ve ark. (2003) tarafindan geliştirilen ve Basım ve Çetin (2011) tarafindan Türkçeye uyarlanan "Yetişkinler İçin Psikolojik Dayanıklılık Ölçeği”, 33 sorudan oluşan 5'li likert tipi bir ölçme aracıdır. Ölçekten elde edilebilecek en düşük puan 33 ve en yüksek puan da 165 'tir. Ölçekten alınan puanlar arttıkça katılımcıların psikolojik dayanıklılık düzeylerinin $\operatorname{arttığ} 1$ şeklinde yorumlanmaktadır. Cevap kutucuklarının soldan sağa doğru 1-5 olarak değerlendirilerek; 1,3,4,8,11,12,13,14,15,16,23,24,25, 27,31,33 numaral1 sorular ters kodlanır. Alt1 faktörlü ölçekte 'yapısal stil' $(3,9,15,21)$ ve 'gelecek algis1' $(2,8,14,20)$ 4'er madde; 'aile uyumu' $(5,11,17,23,26,32)$, 'kendilik algisı' $(1,7,13,19$, $28,31)$ ve 'sosyal yeterlilik' $(4,10,16,22,25,29)$ 6 'şar madde ve 'sosyal kaynaklar' $(6,12,18,24$, 27,30,33) ise 7 madde ile ölçülmektedir (13). Ölçeğin Cronbach Alfa katsayısı 0.86 olup (13), bu araştırmada ise, ölçek toplam puan Cronbach Alfa iç tutarlık katsayısı 0.89 olarak hesaplanmıştır.

\subsection{Verilerin analizi}

Araştırma sonucunda elde edilen verilerin analizi bilgisayar ortamında SPSS 20 paket programı ile yapılmıştır. Verilerin değerlendirilmesinde tanımlayıc1 istatistikler, Kolmogorov-Smirnov, Mann Whitney-U, analizleri kullanılmıştır. Sonuçlar 
\%95 güven aralığında ve $\mathrm{p}<0.05$ anlamlılık düzeyinde değerlendirilmiştir.

\subsection{Araştırma etiği}

Araştırma öncesinde Ege Üniversitesi Tıbbi Araştırmalar Etik Kurulu'ndan (TAEK Karar no: 9-5.1T/56) onay ve hastaya bakım veren aile üyelerinden aydınlatılmış onam alındı.

\subsection{Araştırmanın sınırlılıkları}

Araştırma Tepecik Eğitim ve Araştırma Hastanesi Nefroloji-Diyaliz Ünitesinde takip edilen hastaların aileleriyle sinırlıdır.

\section{BULGULAR}

Bakım verenler ile çocuklarının sosyodemografik ve bireysel özellikleri Tablo 1, Tablo 2 ve Tablo 3 'te verilmiştir.

Bakım verenlerin Psikolojik Dayanıklılık Ölçeği ve alt boyutlarından aldikları puan ortalamaları ve alt ve üst sınır puanları Tablo 4'te verilmiştir. Toplam ölçek puan ortalaması 110.91 olup, ölçek değerlendirmesi puan arttıkça psikolojik dayanıklilik artar şeklinde yorumlanmaktadır.

Tablo 1. Bakım verenlerin çocuklarının sosyodemografik ve bireysel özelliklerine göre dağılımları (n=53)

\begin{tabular}{|l|c|c|}
\hline Değişkenler & Sayı & Yüzde \\
\hline Yaş grubu & 5 & 9.4 \\
$3-12$ yaş & 15 & 28.3 \\
$13-17$ yaş & 33 & 62.3 \\
18 yaş ve üzeri & & 39.6 \\
\hline Cinsiyet & 21 & 60.4 \\
Kadın & 32 & \\
Erkek & & 30.2 \\
\hline Tanı aldığı yaş & 16 & 35.8 \\
$0-5$ yaş & 19 & 34.0 \\
6-11 yaş & & \\
12 yaş ve üzeri & 23 & 43.4 \\
\hline Kaç yıl önce nakil olduğu & 21 & 39.6 \\
$1-4$ yıl & 9 & 17.0 \\
5-8 yıl & & \\
9 yıl ve üzeri & & \\
\hline
\end{tabular}


Tablo 2. Bakım verenlerin sosyodemografik ve bireysel özelliklerine göre dağılımları ( $n=53)$

\begin{tabular}{|c|c|c|}
\hline Değișkenler & Sayı & Yüzde \\
\hline \multicolumn{3}{|l|}{ Yakınlık derecesi } \\
\hline Anne & 40 & 75.5 \\
\hline Baba & 10 & 18.9 \\
\hline Diğer (amca, dede ve abi) & 3 & 5.6 \\
\hline \multicolumn{3}{|l|}{ Yaşı } \\
\hline $32-39$ & 13 & 24.5 \\
\hline $40-47$ & 18 & 34.0 \\
\hline 48 ve üzeri & 22 & 41.5 \\
\hline \multicolumn{3}{|l|}{ Cinsiyeti } \\
\hline Kadın & 42 & 79.2 \\
\hline Erkek & 11 & 20.8 \\
\hline \multicolumn{3}{|l|}{ Mesleği } \\
\hline Çalışmayan(ev hanımı) & 37 & 69.8 \\
\hline Çalışan (memur, aşçı, işçi, çiftçi vb.) & 16 & 30.2 \\
\hline \multicolumn{3}{|l|}{ Gelir-gider dengesi } \\
\hline Yetersiz gelir & 25 & 47.2 \\
\hline Yeterli gelir & 28 & 52.8 \\
\hline \multicolumn{3}{|l|}{ Tütün kullanımı } \\
\hline Evet & 9 & 17.0 \\
\hline Hayır & 44 & 83.0 \\
\hline \multicolumn{3}{|l|}{ Alkol kullanımı } \\
\hline Evet & 9 & 17.0 \\
\hline Hayır & 44 & 83.0 \\
\hline \multicolumn{3}{|c|}{ Nakil olan çocuk harici başka çocuğa sahip olma durumu } \\
\hline Evet & 39 & 73.6 \\
\hline Hayır & 14 & 83.0 \\
\hline \multicolumn{3}{|l|}{ Ailede kronik hastalık bulunma durumu } \\
\hline Evet & 8 & 15.1 \\
\hline Hayır & 45 & 84.9 \\
\hline \multicolumn{3}{|l|}{ Çocuğunun nakil olacağını öğrendiğinde ne hissettiği } \\
\hline Olumlu (mutlu, inanamadım, heyecanlandım vb.) & 49 & 92.5 \\
\hline Olumsuz (korku, tedirginlik vb.) & 4 & 7.5 \\
\hline \multicolumn{3}{|l|}{ Destek kaynakları } \\
\hline Psikolojik destek & 14 & 26.4 \\
\hline Sosyal destek (aile) & 22 & 41.5 \\
\hline Her iki desteği de aldım & 15 & 23.3 \\
\hline Hiçbir destek almadım & 2 & 3.8 \\
\hline \multicolumn{3}{|l|}{ Aile içi iletişim } \\
\hline İyi & 40 & 75.5 \\
\hline Kötü & 13 & 24.5 \\
\hline
\end{tabular}


Tablo 3. Bakım verenlerin günlük işlevlerini sürdürme düzeylerine göre dağılımları (n=53)

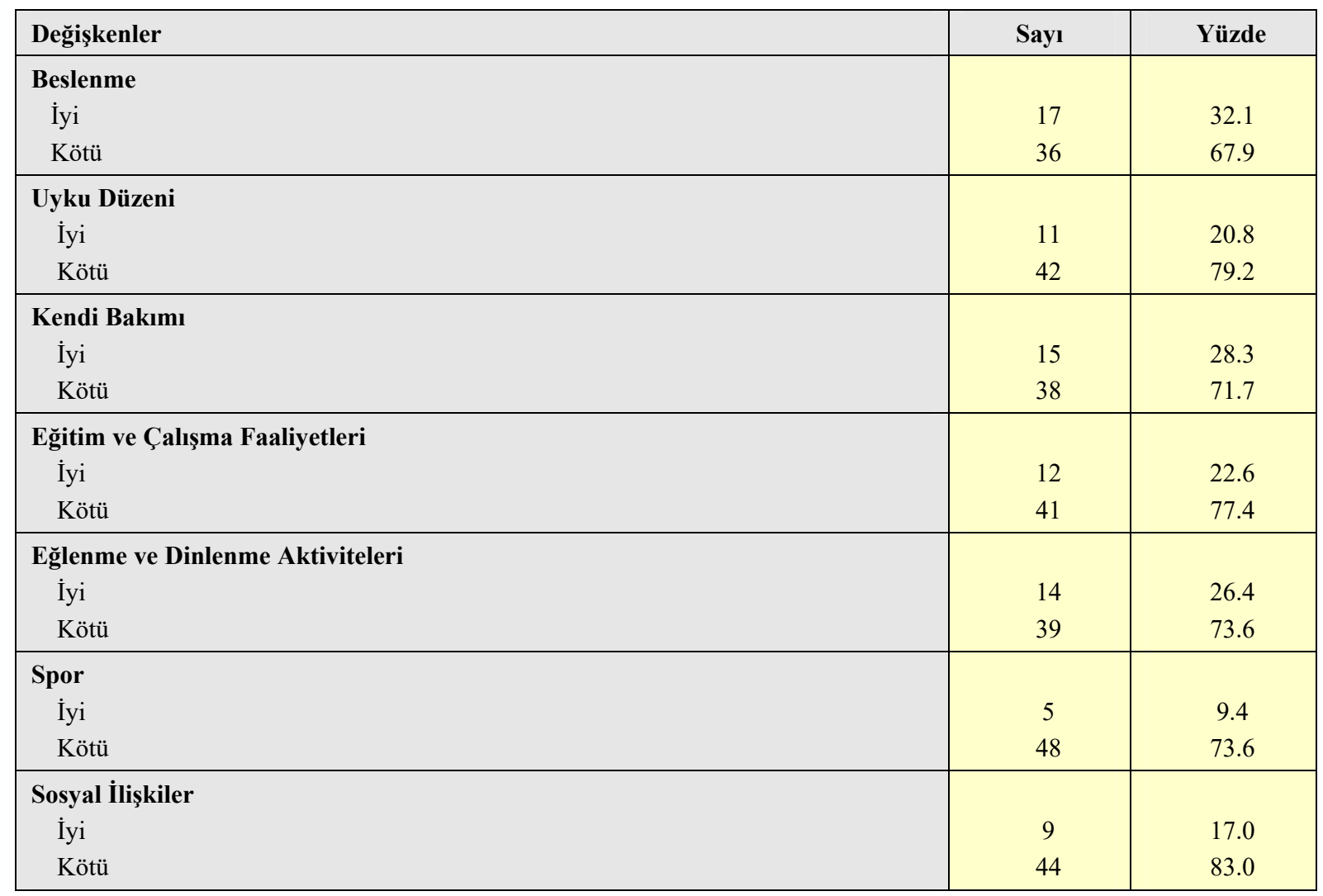

Tablo 4. Bakım verenlerin "psikolojik dayanıklılık ölçeği” alt boyutlarından aldıkları puan ortalamaları (n=53)

\begin{tabular}{|c|c|c|c|c|c|}
\hline $\begin{array}{l}\text { PSİKOLOJIK } \\
\text { DAYANIKLIKLIK ÖLÇEĞİ } \\
\text { BOYUTLARI }\end{array}$ & & Ss & Min & Maks & Puan Aralığı \\
\hline TOPLAM PUAN & 110.91 & 30.73 & 47.00 & 159.00 & $0-165$ puan \\
\hline Kendilik, Alg1s1 Boyutu & 19.87 & 6.42 & 8.00 & 30.00 & $0-30$ puan \\
\hline Gelecek Alg1s1 Boyutu & 12.75 & 4.54 & 4.00 & 20.00 & $0-20$ puan \\
\hline Yapısal Stil Boyutu & 13.30 & 4.24 & 4.00 & 20.00 & $0-20$ puan \\
\hline Sosyal Yeterlilik Boyutu & 19.26 & 6.63 & 8.00 & 30.00 & $0-30$ puan \\
\hline Aile Uyumu Boyutu & 21.45 & 5.59 & 9.00 & 30.00 & $0-30$ puan \\
\hline Sosyal Kaynaklar Boyutu & 24.26 & 6.33 & 10.00 & 35.00 & $0-35$ puan \\
\hline
\end{tabular}


Tablo 5. Katılımcıların Psikolojik Dayanıklılık Ölçeği alt boyutlarından aldıkları puan ortalamaları ile bireysel özelliklerin karşılaştırılması $(\mathrm{n}=53)$

\begin{tabular}{|c|c|c|c|c|c|c|c|c|}
\hline $\begin{array}{l}\text { Psikolojik } \\
\text { Dayanıklılık } \\
\text { Ölçeği } \\
\text { Boyutları }\end{array}$ & $\begin{array}{c}\text { Değişke } \\
\text { n/n } \\
\text { sayısı }\end{array}$ & $\begin{array}{c}\text { Kendilik } \\
\text { Algısı } \\
\text { Boyutu } \\
X \pm \text { SS }\end{array}$ & $\begin{array}{c}\text { Gelecek } \\
\text { Algısı } \\
\text { Boyutu } \\
X \pm \text { SS }\end{array}$ & $\begin{array}{c}\text { Yapisal } \\
\text { Stil } \\
\text { Boyutu } \\
X \pm S S\end{array}$ & $\begin{array}{c}\text { Sosyal } \\
\text { Yeterlilik } \\
\text { Boyutu } \\
\mathbf{X} \pm \mathbf{S S}\end{array}$ & $\begin{array}{c}\text { Aile } \\
\text { Uyumu } \\
\text { Boyutu } \\
\text { X } \pm \text { SS }\end{array}$ & $\begin{array}{c}\text { Sosyal } \\
\text { Kaynakla } \\
\text { r Boyutu } \\
\mathrm{X} \pm \mathrm{SS}\end{array}$ & $\begin{array}{c}\text { PAIS-SR } \\
\mathbf{X} \pm \mathbf{S S}\end{array}$ \\
\hline \multirow{3}{*}{$\begin{array}{l}\text { Ailede kronik } \\
\text { bir hastalığın } \\
\text { varlığı }\end{array}$} & Var $/ 8$ & $24.38 \pm 4.84$ & $15.63 \pm 3.16$ & 16.13 & $24.75 \pm 5.15$ & $24.88 \pm 4.70$ & $28.87 \pm 4.76$ & $134.63 \pm 23.66$ \\
\hline & Yok /45 & $19.07 \pm 6.37$ & $12.25 \pm 4.59$ & $12.80 \pm 4.13$ & $18.29 \pm 6.43$ & $20.85 \pm 5.55$ & $23.44 \pm 6.25$ & $106.69 \pm 30.11$ \\
\hline & Test & $\begin{array}{l}U=93.500 \\
p=0.031\end{array}$ & $\begin{array}{l}U=100.500 \\
p=0.047\end{array}$ & $\begin{array}{l}U=94.500 \\
p=0.033\end{array}$ & $\begin{array}{l}U=80.500 \\
p=0.013\end{array}$ & $\begin{array}{l}U=106.000 \\
p=0.065\end{array}$ & $\begin{array}{l}U=93.000 \\
p=0.030\end{array}$ & $\begin{array}{l}U=85.500 \\
p=0.019\end{array}$ \\
\hline \multirow{3}{*}{$\begin{array}{l}\text { Bakım } \\
\text { verenlerin } \\
\text { transplantasy } \\
\text { ona ilişkin ne } \\
\text { hissettikleri }\end{array}$} & $\begin{array}{l}\text { Olumlu/ } \\
48 \\
\end{array}$ & $19.31 \pm 6.27$ & $12.40 \pm 4.47$ & $12.96 \pm 4.11$ & $18.81 \pm 6.54$ & $21.15 \pm 5.47$ & $23.83 \pm 6.23$ & $108.46 \pm 29.81$ \\
\hline & $\begin{array}{l}\text { Olumsuz/ } \\
5\end{array}$ & $25.20 \pm 5.85$ & $16.20 \pm 4.09$ & $16.60 \pm 4.51$ & $23.60 \pm 6.54$ & $24.40 \pm 6.54$ & $28.40 \pm 6.31$ & $134.40 \pm 32.75$ \\
\hline & Test & $\begin{array}{l}\mathrm{U}=57.000 \\
p=0.055\end{array}$ & $\begin{array}{l}\mathrm{U}=64.000 \\
\mathrm{p}=0.092\end{array}$ & $\begin{array}{l}\mathrm{U}=60.500 \\
\mathrm{p}=0.069\end{array}$ & $\begin{array}{l}\mathrm{U}=80.000 \\
\mathrm{p}=0.237\end{array}$ & $\begin{array}{l}\mathrm{U}=79.000 \\
\mathrm{p}=0.225\end{array}$ & $\begin{array}{l}\mathrm{U}=66.000 \\
\mathrm{p}=0.105\end{array}$ & $\begin{array}{l}\mathrm{U}=60.500 \\
\mathrm{p}=0.069\end{array}$ \\
\hline \multirow{3}{*}{$\begin{array}{l}\text { Günlük } \\
\text { beslenme } \\
\text { alışkanlıkları }\end{array}$} & $\begin{array}{l}\text { İyi } \\
\text { Giden/ } \\
17 \\
\end{array}$ & $21.53 \pm 6.32$ & $14.24 \pm 4.48$ & $14.53 \pm 4.54$ & $21.35 \pm 7.13$ & $23.82 \pm 5.90$ & $26.65 \pm 7.28$ & 122.12 \\
\hline & $\begin{array}{l}\text { Aksayan/ } \\
36\end{array}$ & $19.08 \pm 6.40$ & $12.06 \pm 4.46$ & $12.72 \pm 4.03$ & $18.28 \pm 6.25$ & $20.33 \pm 5.14$ & $23.14 \pm 5.58$ & $105.61 \pm 28.49$ \\
\hline & Test & $\begin{array}{l}\mathrm{U}=231.000 \\
\mathrm{p}=0.152\end{array}$ & $\begin{array}{l}\mathrm{U}=210.500 \\
\mathrm{p}=0.068\end{array}$ & $\begin{array}{l}\mathrm{U}=222.000 \\
\mathrm{p}=0.108\end{array}$ & $\begin{array}{l}\mathrm{U}=212.500 \\
\mathrm{p}=0.074\end{array}$ & $\begin{array}{l}\mathrm{U}=203.000 \\
\mathrm{p}=0.049\end{array}$ & $\begin{array}{l}\mathrm{U}=204.500 \\
\mathrm{p}=0.052\end{array}$ & $\begin{array}{l}U=195.00 \\
p=0.034\end{array}$ \\
\hline \multirow{3}{*}{$\begin{array}{l}\text { Özbakım } \\
\text { becerileri }\end{array}$} & $\begin{array}{l}\text { İyi } \\
\text { Giden/ } \\
15 \\
\end{array}$ & $23.60 \pm 4.12$ & $15.13 \pm 3.02$ & $15.73 \pm 3.24$ & $24.07 \pm 5.40$ & $24.20 \pm 5.57$ & $28.33 \pm 5.27$ & $131.07 \pm 22.69$ \\
\hline & $\begin{array}{l}\text { Aksayan/ } \\
38\end{array}$ & $18.39 \pm 6.60$ & $11.81 \pm 4.72$ & $12.34 \pm 4.24$ & $17.37 \pm 6.14$ & $20.37 \pm 5.28$ & $22.66 \pm 6.03$ & $102.95 \pm 30.05$ \\
\hline & Test & $\begin{array}{l}U=152.500 \\
p=0.009\end{array}$ & $\begin{array}{l}U=162.500 \\
p=0.015\end{array}$ & $\begin{array}{l}\mathrm{U}=149.000 \\
\mathrm{p}=0.007\end{array}$ & $\begin{array}{l}\mathrm{U}=114.500 \\
\mathrm{p}=0.001\end{array}$ & $\begin{array}{l}\mathrm{U}=171.000 \\
\mathrm{p}=0.024\end{array}$ & $\begin{array}{l}U=144.500 \\
p=0.005\end{array}$ & $\begin{array}{l}\mathrm{U}=125.000 \\
\mathrm{p}=0.002\end{array}$ \\
\hline \multirow{3}{*}{$\begin{array}{l}\text { Günlük uyku } \\
\text { düzenleri }\end{array}$} & $\begin{array}{l}\text { İyi } \\
\text { Giden/ } \\
11\end{array}$ & $22.36 \pm 5.61$ & $13.82 \pm 3.87$ & $14.18 \pm 2.96$ & $20.64 \pm 6.38$ & $22.91 \pm 5.13$ & $26.10 \pm 5.89$ & $120.00 \pm 26.42$ \\
\hline & $\begin{array}{l}\text { Aksayan/ } \\
42\end{array}$ & $19.21 \pm 6.51$ & $12.47 \pm 4.70$ & $13.07 \pm 4.52$ & $18.90 \pm 6.73$ & $21.07 \pm 5.70$ & $23.79 \pm 6.41$ & $108.52 \pm 31.62$ \\
\hline & Test & $\begin{array}{l}U=161.000 \\
p=0.124\end{array}$ & $\begin{array}{l}U=186.000 \\
p=0.322\end{array}$ & $\begin{array}{l}U=193.000 \\
p=0.409\end{array}$ & $\begin{array}{l}U=187.500 \\
p=0.338\end{array}$ & $\begin{array}{l}U=192.500 \\
p=0.397\end{array}$ & $\begin{array}{l}U=185.500 \\
p=0.317\end{array}$ & $\begin{array}{l}U=171.000 \\
p=0.188\end{array}$ \\
\hline \multirow{3}{*}{$\begin{array}{l}\text { Eğitim ve } \\
\text { çalışma } \\
\text { yaşamları }\end{array}$} & $\begin{array}{l}\text { İyi Giden/ } \\
12\end{array}$ & $21.33 \pm 7.35$ & $13.17 \pm 4.91$ & $13.83 \pm 4.45$ & $21.33 \pm 7.63$ & $22.00 \pm 6.02$ & $24.92 \pm 7.37$ & $116.58 \pm 36.66$ \\
\hline & $\begin{array}{l}\text { Aksayan/ } \\
41\end{array}$ & $19.44 \pm 6.15$ & $12.63 \pm 4.82$ & $13.15 \pm 4.22$ & $18.66 \pm 6.29$ & $21.29 \pm 5.52$ & $24.07 \pm 6.08$ & $109.24 \pm 29.08$ \\
\hline & Test & $\begin{array}{l}U=201.500 \\
\mathrm{P}=0.343\end{array}$ & $\begin{array}{l}\mathrm{U}=227.000 \\
\mathrm{P}=0.685\end{array}$ & $\begin{array}{l}\mathrm{U}=224.000 \\
\mathrm{P}=0.639\end{array}$ & $\begin{array}{l}U=191.500 \\
P=0.245\end{array}$ & $\begin{array}{l}\mathrm{U}=234.000 \\
\mathrm{P}=0.798\end{array}$ & $\begin{array}{l}\mathrm{U}=222.500 \\
\mathrm{P}=0.617\end{array}$ & $\begin{array}{l}\mathrm{U}=207.500 \\
\mathrm{P}=0.413\end{array}$ \\
\hline \multirow{3}{*}{$\begin{array}{l}\text { Eğlenme ve } \\
\text { dinlenme } \\
\text { aktiviteleri }\end{array}$} & $\begin{array}{l}\text { İyi Giden/ } \\
14\end{array}$ & $21.64 \pm 6.59$ & $13.42 \pm 4.38$ & $14.64 \pm 4.16$ & $22.29 \pm 7.22$ & $22.64 \pm 6.21$ & $26.07 \pm 7.43$ & $120.71 \pm 33.47$ \\
\hline & $\begin{array}{l}\text { Aksayan/ } \\
39\end{array}$ & $19.23 \pm 6.31$ & $12.51 \pm 4.63$ & $12.82 \pm 4.22$ & $18.18 \pm 6.15$ & $21.02 \pm 5.37$ & $23.62 \pm 5.85$ & $107.38 \pm 29.35$ \\
\hline & Test & $\begin{array}{l}\mathrm{U}=209.000 \\
\mathrm{P}=0.195\end{array}$ & $\begin{array}{l}\mathrm{U}=237.500 \\
\mathrm{P}=0.472\end{array}$ & $\begin{array}{l}\mathrm{U}=204.000 \\
\mathrm{P}=0.162\end{array}$ & $\begin{array}{l}\mathrm{U}=178.500 \\
\mathrm{P}=0.056\end{array}$ & $\begin{array}{l}\mathrm{U}=228.500 \\
\mathrm{P}=0.368\end{array}$ & $\begin{array}{l}\mathrm{U}=205.000 \\
\mathrm{P}=0.169\end{array}$ & $\begin{array}{l}\mathrm{U}=193.500 \\
\mathrm{P}=0.109\end{array}$ \\
\hline \multirow{3}{*}{$\begin{array}{l}\text { Spor } \\
\text { alışkanlıkları }\end{array}$} & $\begin{array}{l}\text { İyi Giden/ } \\
5\end{array}$ & $19.40 \pm 6.43$ & $12.20 \pm 5.45$ & $13.00 \pm 4.90$ & $19.40 \pm 7.33$ & $21.20 \pm 6.38$ & $24.00 \pm 7.75$ & $109.20 \pm 37.29$ \\
\hline & $\begin{array}{l}\text { Aksayan/ } \\
48\end{array}$ & $19.92 \pm 6.48$ & $12.81 \pm 4.50$ & $13.33 \pm 4.22$ & $19.25 \pm 6.64$ & $21.48 \pm 5.57$ & $24.29 \pm 6.26$ & $111.08 \pm 30.44$ \\
\hline & Test & $\begin{array}{l}\mathrm{U}=116.000 \\
\mathrm{P}=0.918\end{array}$ & $\begin{array}{l}U=109.500 \\
P=0.757\end{array}$ & $\begin{array}{l}\mathrm{U}=112.500 \\
\mathrm{P}=0.825\end{array}$ & $\begin{array}{l}\mathrm{U}=117.500 \\
\mathrm{P}=0.941\end{array}$ & $\begin{array}{l}U=114.500 \\
P=0.871\end{array}$ & $\begin{array}{l}\mathrm{U}=111.000 \\
\mathrm{P}=0.802\end{array}$ & $\begin{array}{l}\mathrm{U}=117.00 \\
\mathrm{P}=0.941\end{array}$ \\
\hline \multirow{3}{*}{$\begin{array}{l}\text { Sosyal } \\
\text { ilişkileri }\end{array}$} & $\begin{array}{l}\text { İyi Giden/ } \\
9\end{array}$ & $22.22 \pm 6.26$ & $13.66 \pm 4.53$ & $14.33 \pm 4.15$ & $22.22 \pm 7.01$ & $22.44 \pm 6.27$ & $26.22 \pm 7.05$ & $121.11 \pm 33.75$ \\
\hline & $\begin{array}{l}\text { Aksayan } \\
\text { /44 }\end{array}$ & $19.39 \pm 6.41$ & $12.57 \pm 4.57$ & $13.09 \pm 4.27$ & $18.66 \pm 6.47$ & $21.25 \pm 5.49$ & $23.86 \pm 6.18$ & $108.82 \pm 30.07$ \\
\hline & Test & $\begin{array}{l}U=146.500 \\
P=0.227\end{array}$ & $\begin{array}{l}\mathrm{U}=167.000 \\
\mathrm{P}=0.476\end{array}$ & $\begin{array}{l}\mathrm{U}=163.000 \\
\mathrm{P}=0.420\end{array}$ & $\begin{array}{l}U=131.000 \\
P=0.116\end{array}$ & $\begin{array}{l}U=178.000 \\
P=0.650\end{array}$ & $\begin{array}{l}\mathrm{U}=161.000 \\
\mathrm{P}=0.394\end{array}$ & $\begin{array}{l}\mathrm{U}=145.500 \\
\mathrm{P}=0.218\end{array}$ \\
\hline
\end{tabular}

Ailede kronik bir hastalığın olma durumu ile Psikolojik Dayanıklılık Ölçeği alt boyut puan ortalamaları karşılaştırıldığında; kronik hastalık var diyenlerin kendilik algıs1, gelecek alg1s1, yapısal stil, sosyal yeterlilik, sosyal kaynaklar alt boyutunda puan ortalamaları istatistiksel olarak anlamlı düzeyde yüksektir $(\mathrm{p}<0,05)$ ve psikolojik dayanıklılık bu alt boyutlarda artmıştır. Aile 
uyumu boyutunda ise istatistiksel olarak anlaml bir fark olușturmadığ 1 belirlenmiștir ( $\mathrm{p}>0,05$, Tablo 5).

Aile üyelerinin, çocuklarının böbrek nakli olacağını öğrendiklerinde ne hissettikleri ile Psikolojik Dayanıklılık Ölçeği toplam ve alt boyut puanları arasındaki ilişki incelendiğinde, istatistiksel olarak anlamlı bir fark yoktur ( $\mathrm{p}>0,05$, Tablo 5).

Bakım verenlerin günlük beslenme alışkanlıkları ile Psikolojik Dayanıklılık Ölçeği toplam ve alt boyut puanları arasındaki ilişki incelendiğinde, yalnızca toplam ölçekte istatistiksel olarak anlamlı bir fark yarattığ 1 belirlenmiştir $(\mathrm{p}<0,05)$. Günlük beslenme alışkanlığı iyi giden bireylerde dayanıklılık artırmıştır. Diğer alt boyutlarda ise anlamlı bir değişiklik oluşturmadığ 1 belirlenmiştir ( $\mathrm{p}>0,05$, Tablo 5).

Bakım verenlerin günlük özbakım becerileri ile Psikolojik Dayanıklılık Ölçeği toplam ve alt boyut puanları karşılaştırıldığında, tüm alt boyutlarda istatistiksel olarak anlamlı fark olduğu belirlenmiştir $(p<0,05)$. Özbakım becerileri iyi olan bireylerde psikolojik dayanıklılık puanları artmıştır (Tablo 5).

Bakım verenlerin günlük uyku düzeni, eğitim ve çalışmalarının, eğlenme ve dinlenme aktivitelerinin ve spor alışkanlıklarının düzenli olup olmaması ve sosyal ilişkileri ile Psikolojik Dayanıklılık Ölçeği toplam ve alt ölçek puanları karş1laştırıldığında, istatistiksel olarak anlamlı bir fark yoktur ( $>>0,05$, Tablo 5).

\section{TARTIŞMA}

Çocukları böbrek transplantasyonu olan ailelerin psikolojik dayanıklılıklarını inceleyen ve dayanıklılı̆g1 etkileyen faktörleri belirleyen araştırmada, elde edilen bulgular ile ilgili literatür yetersiz olduğu için daha çok ilişkili faktörleri içeren literatür ile tartışılmıştır.

Çalışmada organ transplantasyonu olan çocukların cinsiyeti, yaşı, nakil yılı ve tanı aldığ 1 yaşları ile bakım verenlerin psikolojik dayanaklılık puanları arasında istatistiksel olarak anlamlı bir fark yoktur. Yapılan bazı çalışmalar nakil için bekleme süresinin artmasının aile ve hasta için stres, anksiyete, çaresizlik ve umutsuzluk duygu- larına neden olabileceğini bildirmiştir (14). Yine yapılan çalışmalarda nakil süresi bir yılı geçenlerde, genel olarak yaşam kalitesinin arttığ bildirilmektedir (15- 17). Bu faktörlerin bakım verenleri de psikolojik dayanıklılık açısından etkileyebileceği öngörülmesine rağmen anlamlı bir fark saptanmamıştır. Oysa psikolojik dayanıklılık literatüründe hem risk, hem de koruyucu faktörlerin bireysel, ailesel ve çevresel faktörlerden etkilendiği birçok yayın ve araştırmanın ortak sonucu olarak bildirilmektedir (18). Hatta bu nedenle bazı araştırmacılar psikolojik dayanıklılı̆̆1 ekolojik kuram bağlamında ele almışlardır (19). Bu sonuç beklenen yönde değildir.

Bakım verenin psikolojik sağlamlık puanları cinsiyet değişkeni açısından incelendiğinde fark istatistiksel olarak anlamlı değildir. Bu bulguyu destekleyen araştırma sonuçları mevcuttur (2022). Bunun tersine, literatürde psikolojik sağlamlığı etkileyebileceği düşünülen faktörlerden biri cinsiyet olarak belirtilmiştir (20). Bu anlamda, psikolojik dayanıklılık düzeyleri kadın ya da erkeklerde daha yüksek olduğunu gösteren çalışmalar da vardır $(23,24)$.

Gelir düzeyi psikolojik dayanıklılıkta etkili faktörlerdendir $(25,26)$. Bakım verenlerin gelir düzeyi toplam dayanaklılık ölçeği puanlarına göre incelendiğinde; psikolojik dayanaklılık toplam ve alt boyutlarında anlamlı değişiklik oluşturduğu belirlenmiş̧tir. $\mathrm{Bu}$ anlamda araştırma sonuçları literatürle uyumludur (23).

Ailede kronik bir hastalığın varlığg psikolojik dayanıklılığı etkilemektedir (25). Bu çalışmada, ailede kronik hastalık varlığında kendilik algıs1, gelecek algis1, yapisal stil, sosyal yeterlilik, sosyal kaynaklar boyutunda psikolojik dayanıklılık artmıştır. Aile uyumu boyutunda ise anlamlı bir fark yoktur. Psikolojik dayanıklılık üzerine yapılan araştırmalar, birey ve aile kaynaklarının genellikle büyük bir sağlık sorunu gibi zorluklar karşısında aktive olduğunu bulmuştur. Daha dirençli olma, genellikle hastalık deneyimi ile artar, kişisel gelişim ve daha güçlü bağlar sağlar (27). Patterson (2002), bir ailenin rollerini, kurallarını ve ilişkisel kalıplarını, kronik hastalığ veya engeli olan bir üyenin özel ihtiyaçlarını karşılayacak şekilde yeniden düzenleme yeteneği, savunmasız üyeleri koruma işlevini yerine 
getirmede başarının kanıtı olacaktır demiştir (28). $\mathrm{Bu}$ aileler kronik hastalık riskine maruz kalmaya başarılı bir şekilde yanıt vermek için gereken koruyucu kaynakları geliştirmiştir. Bu koruyucu faktörler, riske maruz kalmadan önce mevcut olabileceği gibi riske cevaben geliştirilmiş ve/ veya güçlendirilmiş de olabilir. Ayrıca ailede kronik hastalık varlığının psikolojik dayanıklılı̆g 1 yükseltmesi durumu travma sonrasi büyüme kavramı ile de ilişkili olabilmektedir. Travma sonrası büyüme kavramını Tedeschi ve ark. (2000); "büyük bir yaşam krizi ile mücadeleden kaynaklanan önemli olumlu değişim deneyimi”" olarak tanımlamışlardır (29). Travmatik olaylar karşısında bireylerin verdikleri tepkiler farklıdır. Travmatik olaylar her zaman bireylerde yıkıcı etki bırakmamakta aksine bazı bireyleri travma öncesi durumdan daha güçlü hale getirebilmektedir (30). Bu durumda daha önce kronik bir hastalıkla karşılaşmış olan aile bireylerinin hastalığa uyumu daha kolay hale gelmiş olabilir. ÜzarÖzçetin ve Hiçdurmaz (2017) yaptıkları bir çalışmada psikolojik dayanıklılık ve travma sonrası büyümenin birbiriyle ilişkili olduğunu; bu iki kavramın travmatik yaşantılardan sonra bireylerin yaşanan süreçten en az zararla çıkabilmelerine olanak sağladığını belirtmişlerdir (31).

Bir çocuğun kaybı, ebeveyn kaybı ve çocukta bir kronik hastalık teşhisi gibi beklenmeyen yaşam olaylarının, bir ailenin işlevlerini aşırı uç noktalara iten bir yönü vardır. Stresörler ailelerde işleyişi çok daha kötü ya da çok daha güçlü hale getirir (32). Bakım verenlerin psikolojik dayanıklılık puanları ile çocuklarının böbrek nakli olacağını öğrendiklerinde neler hissettiklerine göre dağılımı incelendiğinde; Psikolojik Dayanıklılık Ölçeği toplam ve alt boyut puanlarında anlamlı bir değişiklik yaratmadığı belirlenmiştir. $\mathrm{Bu}$ durum nakil sürecini istenen ve olumlu bir durum olarak algılama oranının çok yüksek olmasıyla ilişkili olabilir.

Günlük yaşam aktiviteleri açısından incelediğimizde bakım verenler büyük oranda günlük yaşam aktivitelerinin aksadığını belirtmişlerdir. Belasco ve Sesso (2002), diyaliz hastalarına bakım veren aile üyelerinin bakım yükü ve yaşam kalitelerini incelemek amacıyla yaptıkları çalışmalarında, bakım yüklerinin yüksek ve yaşam kalitelerinin ise düşük olduğunu belirtmişlerdir (33) ve yaşam kalitesi psikolojik dayanıklılığın olumlu bir sonucu olarak ele alınmaktadır (34). Oranı düşük olsa da, bakım verenlerin beslenme alışkanlığı iyi olanlarda toplam ölçek dayanıklılık puanlarını artırmıştır. Ayrıca özbakım becerileri iyi olan bireylerde de dayanıklılık artmıştır. Uyku, düzenli eğitim-çalışma hayatı, düzenli spor alışkanlığı, sosyal ilişkileri, eğlenme ve dinlenme aktiviteleri büyük oranda aksamasına rağmen istatiksel olarak anlamlı bir fark oluşturmadığ 1 belirlenmiştir. Shyu ve arkadaşları (2000), bakım veren aile bireylerinin kendi gereksinimlerini ve kariyer planlarını gerçekleştiremediklerini ifade etmişlerdir (35). Psikolojik dayanıklılığa bireysel alanın etkisi (18) düşünüldüğünde bu beklenen bir durum değildir. Bu nedenle farkın istatistiksel olarak anlamlı olmaması örneklemdeki günlük yaşam aktiviteleri ve bireysel gereksinimlerini karşılama durumu iyi olan bireylerin sayısının nispeten az olması ile ilişkili olabilir. Ya da bakım verenlerin; günlük yaşam aktiviteleri, sosyal, entelektüel gereksinimleri ve kendini gerçekleştirme boyutuna ilgi gösteremediği ve bunun özgeci bir davranış olarak kabul görüyor olabileceği şeklinde yorumlanabilir.

\section{SONUÇ}

Ailede başka kronik hastalığ günlük beslenme alışkanlığı ve özbakım becerileri iyi olan bakım verenlerin psikolojik dayanıklılığı yüksek bulunmuştur. $\mathrm{Bu}$ da, bakım verenlerin kendileriyle ilgili minimum düzeyde gereksinimleriyle meşgul olduğunu göstermiştir. Günlük uyku düzeni, eğitim ve çalışma faaliyetleri, dinlenme ve eğlenme aktiviteleri, spor alışkanlıkları ve sosyal ilişkiler alanında bakım verenlerin çoğunluğu iyi olmadığını bildirmiştir. Yaşamı değiştiren kronik hastalıklarda uzman psikiyatri hemşireleri hastanın ve ailenin hastalık ve etkileriyle başa çıkma, hayattan anlam bulma, uyum becerileri geliştirme, bakım ve öz bakımı dengelemeye kadar kapsamlı bir alanda danışmanlık ve psikolojik müdahalelerde bulunmalıdır. Aile dayanıklılığı ve kronik hastalık ilişkisi toplum sağlığı için disiplinler arası işbirliği ile geniş perspektiften ele alınması gereken bir konudur ve tüm sağl1k disiplinleri işbirliği içinde çalışmalar yürütmelidir. 


\section{Kaynaklar}

1. Kaçmaz N, Barlas Ünsal G. Karaciğer Nakli Yapılan Hasta ve Hasta Yakınlarının Psikososyal Durumlarının Yaşam Kalitesi Üzerine Etkisi. Journal of Psychiatric Nursing/Psikiyatri Hemsireliği Dergisi 2014;5(1):1-8.

2. Harambat J, Cochat P. Growth after renal transplantation, Pediatric Nephrology, 2009; 24(7):1297-1306.

3. Özdağ N. Organ nakli ve bağışına toplumun bakışı. Cumhuriyet Üniversitesi Hemşirelik Y.O. Dergisi 2001;5: 46-55.

4. Anthony S.J et al. Child and parental perspectives of multidimensional quality of life outcomes after kidney transplantation. Pediatric transplantation 2010; 14(2): 249-256.

5. Atagün M.İ et al. Kronik hastalıklarda bakım veren yükü. Psikiyatride Güncel Yaklaşımlar 2011; 3(3):513-552.

6. Martin S.C et al. Medical, personal, and social forms of uncertainty across the transplantation trajectory.Qualitative Health Research 2010;20(2):182-196.

7. Sundaram S. S et al. Adolescent health-related quality of life following liver and kidney transplantation. American Journal of Transplantation 2007;7(4): 982-989.

8. Hunter A, A Cross-culturalComparison of Resilience in Adolescents. Journal Pediatric Nursing 2001;16(3):172-179.

9. Tusaie K, Janyce D. Resilience: A historical review of the construct. Holistic nursing practice 2004; 18 (1): 3-10.

10. Wagnild G.M, Young H.M. Development and psychometric. Journal of nursing measurement 1993;1(2) 165-78.

11. Kavi E, Karakale B. Çalışan psikolojisi açısından psikolojik dayanıklılık. Hak İş Uluslararası Emek ve Toplum Dergisi 2018;7(17): 55-77.

12. Çetin F,Basım H.N, Psikolojik Dayanıklılığın İş Tatmini ve Örgütsel Bağlılık Tutumlarındaki Rolü, “İ̧̧;GÜÇ” Endüstri İlişkileri ve İnsan Kaynakları Dergisi 2011;13(03):79-94.

13. Basim H.N, Çetin F. Yetişkinler için Psikolojik Dayaniklilik Ölçeği'nin Guvenilirlik ve Geçerlilik Çalişmasi. Türk Psikiyatri Dergisi 2011;22(2):104-114

14. Küçük L. Diyaliz hastalarına uygulanan sorun çözme eğitiminin anksiyete depresyon ve başetme biçimlerine etksi. Doktora Tezi. Marmara Üniversitesi 2006.

15. Lumsdaine J. A et al. Higher quality of life in living donor kidney transplantation: prospective cohort study. Transplant international 2005;18(8) 975-980.

16. Üstündağ H et al. Böbrek nakli yapılan hastalarda yaşam kalitesi. Fırat Sağlık Hizmetleri Dergisi 2007;2(6): 117-126.

17. Balaska A et al. Changes in health-related quality of life in Greek adult patients 1 year after successful renal transplantation. Experimental and clinical transplantation: official journal of the Middle East Society for Organ Transplantation 2006; 4(2): 521-524.

18. Öz F, Bahadır Y.E. Ruh sağlığının korunmasında önemli bir kavram: Psikolojik sağlamlık. Hacettepe Üniversitesi Hemşirelik Fakültesi Dergisi 2009;16(3). 82-89.

19. Luthar S.S, Cicchetti. D and Becker B. The construct of resilience: A critical evaluation and guidelines for future work. Child development 2000;71(3): 543-562.

20. Aydın M, Egemberdiyeva A. Üniversite Öğrencilerinin Psikolojik Sağlamlık Düzeylerinin İncelenmesi. Türkiye Eğitim Dergisi 2018; 3(1): 37-53.

21. Aydoğdu, T. Bağlanma stilleri, başa çıkma stratejileri ile psikolojik dayanıklılık arasındaki ilişkinin incelenmesi. Yayınlanmamış Yüksek Lisans Tezi. Gazi Üniversitesi Eğitim Bilimleri Enstitüsü, Ankara, 2013.

22. Tümlü Ü.G, Recepoğlu E. Üniversite Akademik Personelinin Psikolojik Dayanıklılık ve Yaşam Doyumu Arasındaki İlişki. Journal Of Higher Education \& Science/Yüksekögretim ve Bilim Dergisi 2013;3(3):205-213.

23. Karademir T, Açak M. Üniversiteli Sporcuların Psikolojik Dayanıklılık Düzeylerinin İncelenmesi. Kahramanmaraş Sütçü İmam Üniversitesi Sosyal Bilimler Dergisi 2019;16(2):803-816.

24. Oktan V, Odacı H, Berber Çelik Ç. Psikolojik doğum sırasının psikolojik sağlamlığın yordanmasındaki rolünün incelenmesi. Abant İzzet Baysal Üniversitesi Eğitim Fakültesi Dergisi, 2014;14(1):140-152.

25. Gizir C. Psikolojik sağlamlık, risk faktörleri ve koruyucu faktörler üzerine bir derleme çalışması. Türk Psikolojik Danışma ve Rehberlik Dergisi 2007;3(28):113-128.

26. Schoon I, Parsons S, Sacker A. Socioeconomic adversity, educational resilience, and subsequent levels of adult adaptation. Journal of Adolescent Research 2004; 19(4): 383-404.

27. Rolland, J.S. Walsh F. Facilitating family resilience with childhood illness and disability. Current opinion in pediatrics 2006; 18(5): 527-538. 
28. Patterson J. M. Understanding family resilience. Journal of clinical psychology 2002; 58(3): 233-246.

29. Duman N. Travma sonrası büyüme ve gelişim. Uluslararası Afro - Avrasya Araştırmaları Dergisi 2019; 4(7):178-184.

30. İnci F, Boztepe H. Travma Sonrası Büyüme: Öldürmeyen Acı Güçlendirir mi? Psikiyatri Hemşireliği Dergisi 2013;4(2):80-84.

31. Sebuktekin D. Travma sonrası büyüme, temel inançlarda sarsılma ve psikolojik dayanıklılık arasındaki ilişkinin incelenmesi, Yayınlanmamış Yüksek Lisans Tezi. Hasan Kalyoncu Üniversitesi 2018.

32. Zimmerman M.A, Arunkumar R. Resiliency research: Implications for schools and policy. Social Policy Report: Society for Research in Child Development 1994; 8(4): 1-20.

33. Belasco A.G, Sesso R. Burden and Quality of Life of Caregivers for Hemodialysis Patients. American Journal of Kidney Diseases. 2002; 39(4): 805-812.

34. Rutter M. Implications of resilience concepts for scientific understanding. Annals of the New York Academy of Sciences, (Resilience in Children). 2006; 1094(1): 1-12.

35. Shyu Y.I. Patterns of Care Giving when Family Care Givers Face Completing Needs. Journal of Advanced Nursing 2000; 31(1): 35-43. 